\title{
Association between socioeconomic position and diabetic foot ulcer outcomes: a population-based cohort study in South Korea
}

Jeong Hyun $\mathrm{Ha}^{1}$, Heejin $\mathrm{Jin}^{2}$ and Ji-Ung Park ${ }^{1 *}$

\begin{abstract}
Background: Low socioeconomic position (SEP) is associated with a high incidence of diabetic foot ulcers (DFUs). However, reports on the association between SEP and DFU outcomes are limited. Therefore, in this study, we investigated this association and determined the prognostic factors of DFU outcomes.

Methods: The total cohort comprised 976,252 individuals. Using probability sampling, we randomly selected a sample of patients by reviewing the data from the Health Insurance Review and Assessment Service database of South Korea during 2011-2015. Residence, household income, and insurance type represented SEP. The primary outcome was amputation, and the secondary outcome was mortality. A multivariate model was applied to identify the predictive factors. Amputation-free survival and overall survival were calculated using the Kaplan-Meier method.

Results: Among 976,252 individuals in the cohort, 1362 had DFUs (mean age $62.9 \pm 12.2$ years; $42.9 \%$ were women). Overall amputation and mortality rates were 4.7 and $12.3 \%$, respectively. Male sex (hazard ratio [HR], $2.41 ; p<0.01$ ), low SEP (HR 5.13, 5.13; $p=0.018)$, ophthalmopathy (HR, 1.89; $p=0.028)$, circulatory complications $(H R, 2.14 ; p=$ $0.020)$, and institutional type $(H R, 1.78 ; p=0.044)$ were prognostic factors for amputation. Old age $(H R, 1.06 ; p<$ $0.01)$, low SEP (HR, 2.65; $p<0.01)$, ophthalmopathy (HR, 1.74; $p<0.01)$, circulatory complications $(H R, 1.71 ; p<0.01)$, and institution type (HR 1.84; $p<0.01)$ were predictors of mortality.

Conclusions: DFU patients with a low SEP are strongly associated with increased amputation and mortality rates. Along with age and comorbidities, SEP could provide the basis for risk assessment of adverse outcomes in DFU. Providing targeted care for this population considering SEP may improve the prognosis.
\end{abstract}

Keywords: Diabetic foot ulcer, Socioeconomic position, Amputation, Mortality

\section{Background}

Diabetic foot ulcers (DFUs) are one of the major complications of neuropathy and microvascular disease in patients with diabetes. The annual incidence and

\footnotetext{
* Correspondence: alfbskan@gmail.com

1 Department of Plastic and Reconstructive Surgery, Seoul National University Boramae Hospital, Seoul National University College of Medicine, Seoul 07061, Republic of Korea

Full list of author information is available at the end of the article
}

prevalence rates of DFU are $1-4 \%$ and $5-10 \%$, respectively, while the lifetime risk of developing DFUs is $15 \%$ in diabetic patients $[1,2]$. DFUs, the major cause of nontraumatic amputation, are known to have a strong correlation with increased morbidity and mortality [3-7]. Amputation may lead to social deprivation and great economic cost.

Several medical factors including atherosclerosis with multiple stenosis, nephropathy, and uncontrolled

(c) The Author(s). 2021 Open Access This article is licensed under a Creative Commons Attribution 4.0 International License, which permits use, sharing, adaptation, distribution and reproduction in any medium or format, as long as you give appropriate credit to the original author(s) and the source, provide a link to the Creative Commons licence, and indicate if changes were made. The images or other third party material in this article are included in the article's Creative Commons licence, unless indicated otherwise in a credit line to the material. If material is not included in the article's Creative Commons licence and your intended use is not permitted by statutory regulation or exceeds the permitted use, you will need to obtain permission directly from the copyright holder. To view a copy of this licence, visit http://creativecommons.org/licenses/by/4.0/ The Creative Commons Public Domain Dedication waiver (http://creativecommons.org/publicdomain/zero/1.0/) applies to the data made available in this article, unless otherwise stated in a credit line to the data. 
diabetes have been reported as predictive factors for amputation and mortality, which are the major outcomes of DFUs [2, 8]. However, socioeconomic factors may also importantly account for these outcomes because DFUs tend to occur as a result of chronic damage of tissues due to poor diabetes control. Diabetes, like other chronic diseases, is associated with socioeconomic position (SEP) [9-11]. Although the development of DFUs is associated with a low SEP [12], only a few reports exist on association between SEP and the prognosis of DFUs [13]. Patients with DFUs require additional comprehensive care with collaborations between primary and specialty care as well as more controlled health behavior. Furthermore, the cost associated with DFU treatment is high. A decreasing amputation rate among persons with diabetes has been reported, although a wide gap exists among societies and populations [14-17].

Equality in health care according to the need has been an important goal for health care policy in South Korea. All citizens of South Korea are covered by a mandatory health insurance system from birth to death. People are designated as National Health Insurance (NHI) or medical aid (MA) beneficiaries according to their insurance status. Most people who are covered under the NHI are associated with a low SEP and are recipients of the National Basic Livelihood Security System in South Korea. Understanding the association between amputation and mortality rate of DFUs with low SEP can lead to the development of health policies that can ameliorate the inequalities among the different SEPs.

This study aimed to determine the association between SEP and DFU outcomes, namely, amputation and mortality, and identify prognostic factors for these outcomes in a South Korean population.

\section{Methods}

We investigated amputation and mortality rates among patients with DFUs in the South Korean population using the database of the National Health Insurance Sharing Service-National Sample Cohort (NHIS-NSC). The amputation and mortality rates based on residence, type of health insurance, type of medical institution, and income status were examined and the comorbidities associated with diabetes were also considered.

\section{Data collection}

Data for the period 2011-2015 were extracted from the database of the NHIS-NSC, a population-based cohort established by the NHIS in South Korea. The NHIS collects data on the diagnosis, treatment, prescription, healthcare utilization, and inpatient and outpatient records [18]. Death records are merged from the Statistics Korea database along with aforementioned information and provided as claims data for research purposes [19].
NHIS database has been widely used for claims databased studies, and its validity is described elsewhere [19, 20] [21].

The disease code for DFU was created in 2011 in South Korea. Until 2010, only disease codes indicating wounds such as gangrene and ulcers were used. Therefore, these patients with DFUs could have been overlooked and not identified. Therefore, to reduce bias, only data from 2011 onward was selected.

The cohort comprised 976,252 people (as of 2011, approximately $1.95 \%$ of the entire Korean population) who were randomly selected to represent the entire South Korean population. Using probability sampling, this random cohort sample was generated representing an individual's total annual medical expenses within each stratum defined by age, sex, eligibility status (employed or self-employed), and income level (10 quartiles for each eligibility status and MA recipients) combinations using the proportional allocations of the 49,936,638 Korean residents in 2011.

\section{Operational definition}

DFU was defined using the Korean Classification of Diseases-6th (KCD-6th) and KCD-7th versions for the period 2011-2012 and after 2013, respectively. Diabetic foot was defined using the KCD code, indicating diabetic foot complications (E1070-1072, E1170-1172, E12701272, E1370-1372, and E1470-1472). Patients with events within 1 year of the first diagnosis were excluded to reduce the possibility of reverse causation.

The data assessed in our study included demographic information such as age, sex, type of health insurance, residence regions, type of medical institutions at first diagnosis, household income, and other diabetes-related complications. The type of health insurance was divided into NHI and MA. The NHI covers approximately $96 \%$ of the total South Korean population, while the remaining $4 \%$ is covered by the MA program, which receives additional public assistance [22]. The hospitals were categorized as primary, secondary, and tertiary teaching hospitals and the areas of residence were divided into metropolitan and non-metropolitan areas. The causes of medical care utilization or death were recorded using the KCD-6th or KCD-7th classification systems. The study subjects were divided into six SEP groups based on insurance type, income level, and residence location (Group 1, MA and non-metropolitan; Group 2, MA and metropolitan; Group 3, low income $\mathrm{NHI}$ and non-metropolitan; Group 4, low income NHI and metropolitan; Group 5, high income NHI and nonmetropolitan; and Group 6, high income NHI and metropolitan). High household income was defined as 8-10 deciles, while low household income was defined as $0-7$ deciles. 
The primary outcome was amputation, and the secondary outcome was mortality. Amputation was defined following the operation codes (N0572, N0573, N0574, N0575). The NHIS-NSC database was merged with death records and the cause of death data from the Statistics Korea database. Hypertensive disease (International Classification of Diseases, 10th Revision [ICD10] codes I10-I15), coronary heart disease (ICD-10 codes I20-I25), cerebrovascular disease (ICD-10 codes I60-I69), and dyslipidemia (ICD-10 code E78) were considered comorbidities.

\section{Statistical analyses}

Descriptive statistics are presented as $n$ for dichotomous variables and means with standard deviations for continuous variables. Fisher's exact test or Pearson's $X^{2}$ test was used for categorical variables, and Student's t-test was used for continuous variables. We used the Cox proportional-hazards model to evaluate the association of possible risk factors with amputation or mortality. Multivariate analysis was performed using Cox regression with factors that showed $p<0.1$ in the univariate analyses. For censored cases, the follow-up duration was calculated from the date of the first diagnosis to the date of amputation or death. For cases not censored, we set the end of the follow-up point as the last date of medical care utilization (December 13, 2015). Amputation-free survival and overall survival were calculated using the Kaplan-Meier method. All statistical analyses were performed using SAS enterprise guide version 7.1 (SAS Inc.,
Cary, NC, USA) and R studio version 3.3 .3 with $p<0.05$ considered statistically significant.

\section{Ethical statement}

The Institutional Review Board of Seoul National University Boramae Medical Center (No. 07-2019-25) granted this study an exemption with regards ethical approval. We did not obtain informed consent because the patients' records and information were anonymized and de-identified before the analyses. The criteria of informed consent is approved by the the Institutional Review Board of Seoul National University Boramae Medical Center. All methods were carried out in accordance with relevant guidelines and regulations. The data used in this study is not publicly available.

\section{Results}

Baseline characteristics of the study subjects

A total of 1289 subjects were identified during the study period from the randomized cohort sample (Fig. 1). The mean age of the patients was 62.9 years, and $42.9 \%$ were females. With respect to health insurance status, $11.1 \%$ were MA beneficiaries while $88.9 \%$ were NHI beneficiaries. Among the NHI beneficiaries, 25.3\% were in the bottom $20 \%$ of the income quartile. When classified by the level of medical institution, $11.9 \%$ were first diagnosed at tertiary teaching hospitals, $21.8 \%$ at general hospitals, and $66.3 \%$ at clinics (in South Korea, institutions with less than 30 beds are classified as clinic). Considering regional location, $82.9 \%$ resided in non-metropolitan areas.

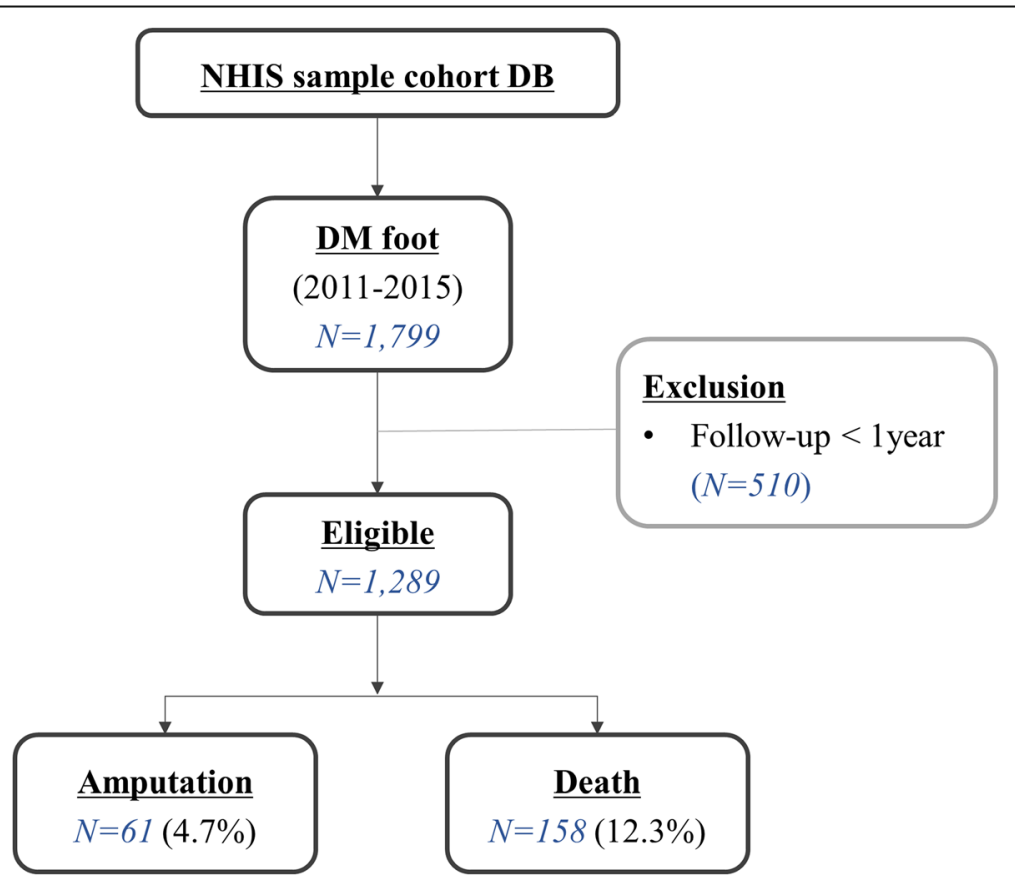

Fig. 1 Flowchart of the selection process for the study population 
According to our SEP group definition, 6.6\% were in group 1 (lowest SEP) and 15\% were in group 6 (highest SEP). Detailed characteristics including comorbidities are listed in Table 1. A consort diagram is shown in Fig. 1.

Table 1 Baseline characteristics

\begin{tabular}{|c|c|}
\hline Variable & $\begin{array}{l}\text { Total }(\%) \\
(N=1289)\end{array}$ \\
\hline Age $(S D)$, years & $62.89(12.2)$ \\
\hline \multicolumn{2}{|l|}{ Sex } \\
\hline Male & $720(55.9)$ \\
\hline Female & $569(44.1)$ \\
\hline Follow-up (range), days & 1214 [776-1606] \\
\hline \multicolumn{2}{|l|}{ Type of health insurance } \\
\hline $\mathrm{NHI}$ & $1146(89.0)$ \\
\hline MA & $143(11.1)$ \\
\hline \multicolumn{2}{|l|}{ Residence regions } \\
\hline Metropolitan & $220(17.1)$ \\
\hline Non-metropolitan & $1069(82.9)$ \\
\hline \multicolumn{2}{|l|}{ Household income } \\
\hline Low (0-7 decile) & $689(53.5)$ \\
\hline High (8-10 decile) & $449(34.9)$ \\
\hline Hypertension & $1061(82.3)$ \\
\hline Dyslipidemia & $1153(89.4)$ \\
\hline Stroke & $526(40.8)$ \\
\hline Cardiovascular disease & $677(52.5)$ \\
\hline Diabetic ophthalmopathy & $268(20.8)$ \\
\hline Diabetic nephropathy & $366(28.4)$ \\
\hline Diabetic neuropathy & $628(48.7)$ \\
\hline Diabetic vasculopathy & $681(52.8)$ \\
\hline \multicolumn{2}{|l|}{ Type of DM } \\
\hline T1DM & $101(7.8)$ \\
\hline $\mathrm{T} 2 \mathrm{DM}$ & $945(73.3)$ \\
\hline Unspecified DM & $243(18.9)$ \\
\hline \multicolumn{2}{|l|}{ Type of institution } \\
\hline Tertiary & $154(11.9)$ \\
\hline Secondary & $281(21.8)$ \\
\hline Primary & $854(66.2)$ \\
\hline \multicolumn{2}{|l|}{ SEP group } \\
\hline 1 & $85(6.6)$ \\
\hline 2 & $58(4.5)$ \\
\hline 3 & $357(27.7)$ \\
\hline 4 & $332(25.8)$ \\
\hline 5 & $256(19.9)$ \\
\hline 6 & $193(15)$ \\
\hline
\end{tabular}

\section{Primary outcome: amputation}

Sixty-one patients (4.7\%) underwent amputation during the follow-up duration of 656 days. Kaplan-Meier curves were generated for overall amputation-free survival (Fig. 2a), and the estimated 5-year amputation-free survival rate was $95.4 \%$. The predictors for amputation are listed in Table 2. Male sex, ophthalmic complication (hazard ratio $[\mathrm{HR}], 1.89$; 95\% confidence interval [CI], 1.07-3.34), circulatory complications (HR, 2.14; 95\% CI, 1.13-4.07), institution type (primary versus secondary general hospital: HR, 1.78; 95\% CI, 1.01-3.12), and low SEP (highest versus lowest: HR, 5.13; 95\% CI, 1.3220.41) were independent predictors for amputation in DFU. The 5-year amputation-free survival rates differed among SEP groups; the 5-year survival rates were 93.0, 82.3, 96.8, 95.0, 95.0, and 98.0\% in groups $1,2,3,4,5$, and 6, respectively (Fig. 3a). HRs for amputation of each SEP group are shown in Fig. 4a.

\section{Secondary outcome: death}

In total, 158 patients (12.3\%) died during the follow-up duration of 880 days. Kaplan-Meier curves were generated for overall survival (Fig. 2b). The estimated 5-year overall survival rate was $78.5 \%$. Older age (HR, 1.06), ophthalmic complications (HR, 1.74; 95\% CI, 1.21-2.49), circulatory complications (HR, 1.71; 95\% CI, 1.15-2.52), institution type (primary versus secondary general hospital: HR, 1.84; 95\% CI, 1.28-2.65), and low SEP (highest versus lowest: $\mathrm{HR}, 2.65$; $95 \% \mathrm{CI}, 1.28-5.52$ ) were independent predictors of mortality in DFU. Independent predictors are listed in Table 3 . The 5 -year overall survival rates differed among the SEP groups; the 5-year survival rates were $65.4,69.5,81.8,83.3,65.5$, and $89.6 \%$ in groups $1,2,3,4,5$, and 6 , respectively (Fig. 3b). HRs for death of each SEP group are shown in Fig. $4 \mathrm{~b}$.

\section{Discussion}

Our study results indicate that a low SEP, reflected by area residence, income level, and type of insurance, is associated with poor outcomes in patients with DFU. Both amputation and mortality rates showed significant differences between the lowest and highest SEP groups. This association was significant after considering age, sex, and comorbidities. Similarly, association between lower SEP and high rate of lower extremity amputation has been reported in peripheral vascular disease [23-26]. While the pathophysiology of peripheral vascular disease overlaps with DFUs, these studies are in line with our results. According to the institution type at first diagnosis, secondary hospitals showed a significantly higher risk than primary hospitals. This may imply that while the phase of referral to specialists in South Korea was performed without delay, patient-related factors such as SEP may have largely affected the prognosis. 
A.

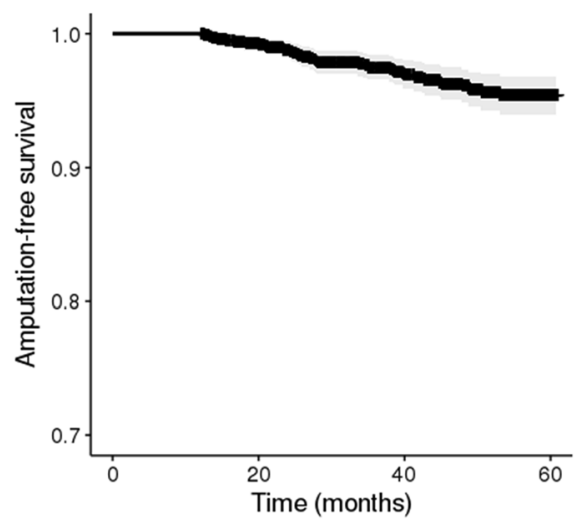

B.

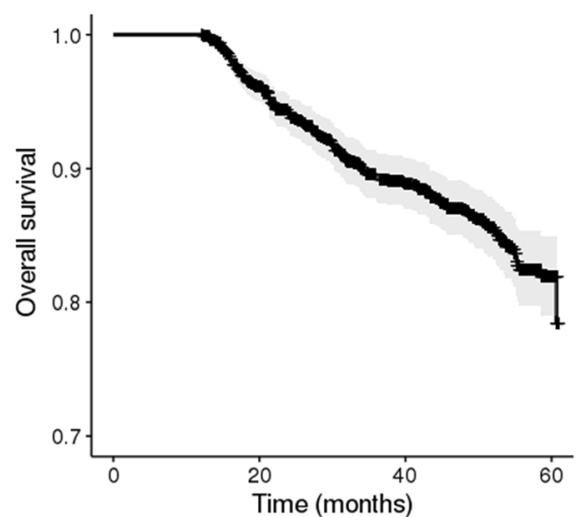

Fig. 2 Kaplan-Meier plots for (a) amputation-free survival and (b) overall survival of patients with diabetic foot ulcers

We investigated factors representing biological mediators for amputation including neuropathy and vasculopathy, and disease severity of diabetes including nephropathy ophthalmopathy. Between the biological mediators, the main etiologies of DFU [27], vasculopathy had more significant impact on DFU outcomes. For the variables representing disease severity, ophthalmopathy but not nephropathy significantly predicted the DFU outcomes in multivariable analysis. Although ophthalmopathy and nephropathy are both considered as typical microvascular complication of diabetes, main pathophysiologic mechanism of ophthalmopathy is retinal ischemia associated with abnormal microvasculature while nephropathy has much more complicated pathophysiology besides microcirculation alterations; structural changes of glomerulus, mesangial expansion and tubulointerstitial fibrosis [28]. Also in line with our results, diabetic retinopathy has been reported to be the predictor for other diabetic complications including DFU [29-33]. These findings consistently suggest that microvascular

Table 2 Cox regression results for Amputation

\begin{tabular}{|c|c|c|c|c|c|c|c|c|}
\hline \multirow[t]{3}{*}{ Variable } & \multicolumn{4}{|c|}{ Univariable analysis } & \multicolumn{4}{|c|}{ Multivariable analysis } \\
\hline & \multirow[t]{2}{*}{$\mathrm{HR}$} & \multirow{2}{*}{$\begin{array}{l}95 \% \mathrm{Cl} \\
\text { Lower }\end{array}$} & \multicolumn{2}{|l|}{$\mathrm{p}$} & \multirow[t]{2}{*}{ HR } & \multirow{2}{*}{$\begin{array}{l}95 \% \mathrm{Cl} \\
\text { Lower }\end{array}$} & \multicolumn{2}{|l|}{$p$} \\
\hline & & & Upper & & & & Upper & \\
\hline Age & 0.998 & 0.977 & 1.019 & 0.840 & - & - & - & - \\
\hline Sex (ref = female) & 1.184 & 0.862 & 1.627 & 0.005 & 2.412 & 1.355 & 4.292 & 0.003 \\
\hline SEP group & & & & 0.059 & & & & 0.047 \\
\hline 1 vs. 6 (ref) & 6.000 & 1.551 & 23.208 & 0.009 & 5.140 & 1.319 & 20.002 & 0.018 \\
\hline 2 vs. 6 (ref) & 6.303 & 1.506 & 26.394 & 0.012 & 5.555 & 1.322 & 23.347 & 0.019 \\
\hline 3 vs. 6 (ref) & 3.484 & 1.026 & 11.829 & 0.045 & 3.252 & 0.955 & 11.071 & 0.059 \\
\hline 4 vs. 6 (ref) & 3.053 & 0.884 & 10.545 & 0.078 & 2.876 & 0.831 & 9.953 & 0.095 \\
\hline 5 vs. 6 (ref) & 3.566 & 1.016 & 12.515 & 0.047 & 3.260 & 0.926 & 11.482 & 0.066 \\
\hline Hypertension (ref =0) & 1.522 & 0.692 & 3.345 & 0.300 & - & - & - & - \\
\hline Stroke $(r e f=0)$ & 1.499 & 0.907 & 2.476 & 0.110 & - & - & - & - \\
\hline Cardiovascular disease $(r e f=0)$ & 1.531 & 0.912 & 2.569 & 0.110 & - & - & - & - \\
\hline Diabetic ophthalmopathy $(r e f=0)$ & 2.597 & 1.553 & 4.341 & 0.001 & 1.893 & 1.072 & 3.343 & 0.028 \\
\hline Diabetic nephropathy $(r e f=0)$ & 1.685 & 1.008 & 2.816 & 0.047 & 1.063 & 0.604 & 1.871 & 0.833 \\
\hline Diabetic neuropathy $(r e f=0)$ & 1.783 & 1.062 & 2.992 & 0.029 & 1.092 & 0.618 & 1.928 & 0.762 \\
\hline Diabetic vasculopathy $(r e f=0)$ & 2.788 & 1.557 & 4.993 & $<0.001$ & 2.141 & 1.127 & 4.066 & 0.020 \\
\hline Type of institution & & & & 0.048 & & & & 0.068 \\
\hline Secondary vs. Primary (ref) & 2.202 & 1.154 & 3.528 & 0.014 & 1.780 & 1.014 & 3.123 & 0.044 \\
\hline Tertiary vs. Primary (ref) & 1.589 & 0.758 & 3.328 & 0.220 & 1.322 & 0.625 & 2.797 & 0.466 \\
\hline
\end{tabular}

SEP Socioeconomic position; ref. Reference; $H R$ Hazard ratio; Cl Confidence interval 
A.

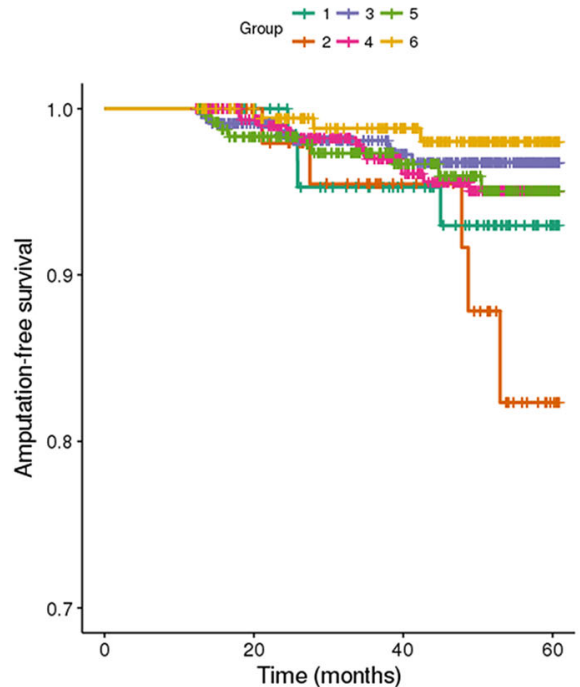

B.

$$
\text { Group } \begin{aligned}
& +1+3+5 \\
& +2+4+6
\end{aligned}
$$

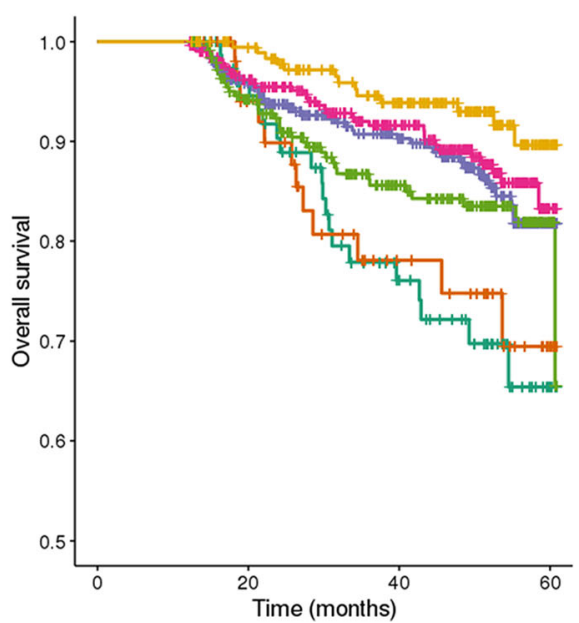

Fig. 3 Kaplan-Meier plots for (a) amputation-free survival and (b) overall survival according to socioeconomic position group

abnormality in diabetes is the key component in predicting DFU outcomes.

We suggest that poor access to care, processes and quality of care, and health behaviors associated with patient education [9] are potential explanations for our results. Poor access to care may be related to a delayed diagnosis. A low SEP population may not be aware of their foot problem, which impedes their clinical visit. Even though the patient perceives their problem, lack of access to adequate primary and advanced care may result in a delay. Poor processes and quality of care may be related to inappropriate treatment. DFUs require early expert assessment and multidisciplinary management in various aspects including infection, peripheral ischemia, and peripheral neuropathy [6]. Close collaboration and timely referral are essential between primary physicians and specialties to improve outcomes [34]. Physicians without awareness of diabetic foot problems may not closely examine the wound, which delays the referral to specialties. Among patients who were referred to specialties, those with a low SEP had poor accessibility to frequent clinical visits because of cost or location. DFUs account for a large proportion of rising health care costs for persons with diabetes $[35,36]$. This would
A.

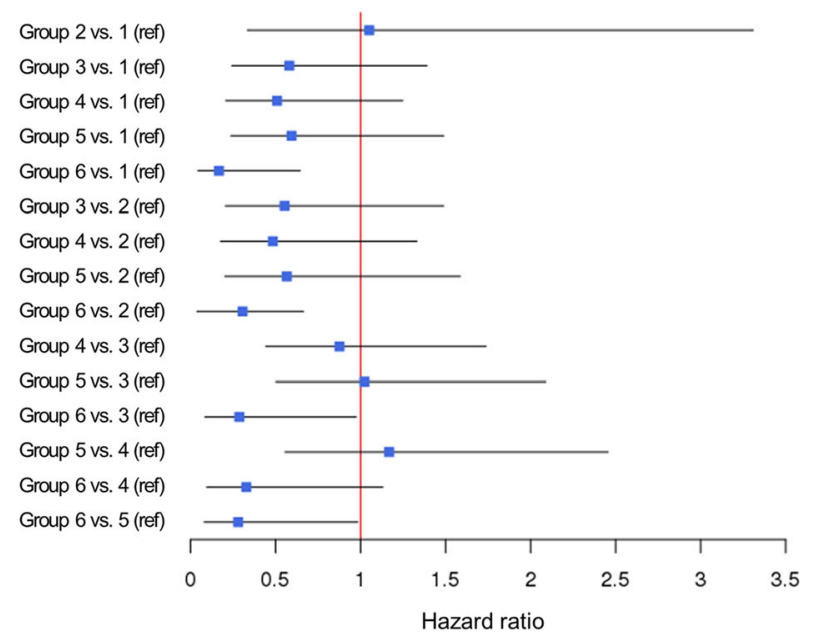

B.

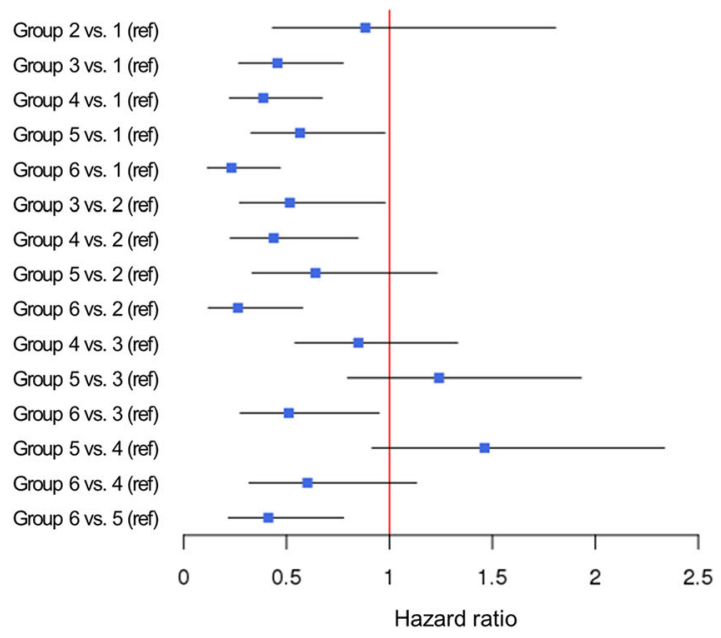

Fig. 4 Forest plot showing hazard ratios of (a) amputation and (b) mortality for socioeconomic position group 
Table 3 Cox regression results for Death

\begin{tabular}{|c|c|c|c|c|c|c|c|c|}
\hline \multirow[t]{3}{*}{ Variable } & \multicolumn{4}{|c|}{ Univariable analysis } & \multicolumn{4}{|c|}{ Multivariable analysis } \\
\hline & \multirow[t]{2}{*}{ HR } & \multirow{2}{*}{$\begin{array}{l}\text { 95\% Cl } \\
\text { Lower }\end{array}$} & \multicolumn{2}{|l|}{$p$} & \multirow[t]{2}{*}{ HR } & \multirow{2}{*}{$\begin{array}{l}\text { 95\% Cl } \\
\text { Lower }\end{array}$} & \multicolumn{2}{|l|}{$p$} \\
\hline & & & Upper & & & & Upper & \\
\hline Age & 1.058 & 1.042 & 1.075 & $<0.001$ & 1.057 & 1.039 & 1.073 & $<0.001$ \\
\hline Sex (ref = female) & 1.184 & 0.862 & 1.627 & 0.300 & - & - & - & - \\
\hline SEP group & & & & $<0.001$ & & & & 0.006 \\
\hline 1 vs. 6 (ref) & 4.289 & 2.132 & 8.621 & $<0.001$ & 3.336 & 1.649 & 6.749 & 0.001 \\
\hline 2 vs. 6 (ref) & 3.789 & 1.728 & 8.302 & 0.001 & 3.672 & 1.666 & 8.094 & 0.001 \\
\hline 3 vs. 6 (ref) & 1.956 & 1.052 & 3.637 & 0.034 & 2.192 & 1.174 & 4.091 & 0.014 \\
\hline 4 vs. 6 (ref) & 1.660 & 0.876 & 3.145 & 0.120 & 1.983 & 1.043 & 3.772 & 0.037 \\
\hline 5 vs. 6 (ref) & 2.425 & 1.239 & 4.575 & 0.006 & 2.251 & 1.182 & 4.283 & 0.013 \\
\hline Hypertension (ref =0) & 2.403 & 1.334 & 4.329 & 0.004 & 0.924 & 0.492 & 1.737 & 0.807 \\
\hline Stroke $(r e f=0)$ & 2.079 & 1.516 & 2.850 & $<0.001$ & 1.234 & 0.882 & 1.725 & 0.219 \\
\hline Cardiovascular disease $(r e f=0)$ & 2.147 & 1.532 & 3.008 & $<0.001$ & 1.275 & 0.879 & 1.849 & 0.199 \\
\hline Diabetic ophthalmopathy $(r e f=0)$ & 2.370 & 1.712 & 3.281 & $<0.001$ & 1.768 & 1.237 & 2.526 & 0.002 \\
\hline Diabetic nephropathy $(r e f=0)$ & 1.767 & 1.284 & 2.433 & $<0.001$ & 1.174 & 0.822 & 1.676 & 0.375 \\
\hline Diabetic neuropathy $(r e f=0)$ & 1.778 & 1.290 & 2.449 & $<0.001$ & 1.033 & 0.727 & 1.470 & 0.852 \\
\hline Diabetic vasculopathy $(r e f=0)$ & 2.523 & 1.777 & 3.582 & $<0.001$ & 1.668 & 1.129 & 2.463 & 0.010 \\
\hline Type of institution & & & & 0.005 & & & & 0.008 \\
\hline Secondary vs. Primary (ref) & 1.789 & 1.255 & 2.549 & 0.001 & 1.776 & 1.237 & 2.550 & 0.002 \\
\hline Tertiary vs. Primary (ref) & 1.482 & 0.936 & 2.345 & 0.093 & 1.415 & 0.885 & 2.260 & 0.147 \\
\hline
\end{tabular}

SEP Socioeconomic position; ref. Reference; HR Hazard ratio; Cl Confidence interval

cause difficulty in accessing care for patients with a low SEP. Sporadic clinical visits prevent frequent evaluations, impeding appropriate education and timely management. Delayed diagnosis, inappropriate treatment, and poor compliance worsen DFUs, increasing the risk of amputation and death.

The strength of this study is that its target sample group was randomly selected which can represent the total South Korean population. Although South Korea provides health insurance coverage for all citizens, blind spots exist, especially for diseases that require meticulous care. The findings from investigations into the prevalence of DFUs and the predictive factors for its prognosis, can guide the rational development of appropriate health care policies. According to our study, the low SEP group may be considered a high-risk group for poor DFU outcomes. While DFUs are associated with high health-related costs in persons with diabetes, patients with a low SEP are more likely to be neglected, which makes it a vicious cycle. DFUs, with amputation as the outcome, are associated with higher health-related costs caused by hospitalization, rehabilitation, home care, and social services for the disabled. Therefore, prevention of amputation through appropriate wound care can be the most important step for cost reduction in these patients. Management health programs will be useful for DFU patients with a low SEP, if provided by the society. Many studies have reported that prevention and screening programs for DFUs can reduce the rates of amputation, re-ulceration, and hospitalization [37-39]. Patout et al. [40] implemented a comprehensive prevention program for lower extremity amputations due to diabetes in Louisiana for low-income African-American populations. This resulted in a profound reduction in DFU-related complications including hospitalization, length of hospital stay, emergency room visits, foot operations, and lower extremity amputations after 1 year. According to a study conducted in the United Kingdom, developing DFU screening and preventive programs cost GB£100,000 (US\$160,000) but saved approximately GB£3000 per amputation [41]. In this regard, diabetic foot management programs for DFU patients with a low SEP would largely reduce amputation and mortality rates, which can further reduce healthrelated costs. Regular foot inspections and education programs can be useful management tools. Education for primary care physicians may also be helpful [42]. The proportion of persons with diabetes undergoing annual foot examination in primary care hospitals is less than 49\% [40]. Especially in South Korea, the proportion was even lower than $10 \%$ following the reports of 2007 [43]. In another study, of diabetic patients, who were admitted for foot infections, only $14 \%$ received fundamental foot examinations [44]. 
Our study has some limitations. First, our data did not include lifestyle, smoking, or health-related clinical factors such as hemoglobin A1c level and body mass index, which could have influenced the outcomes. Second, although the claims data were available from the year 2002, our study only targeted data from the year 2011 onwards because this was the year when the specific disease code for the diabetic foot was generated. This inevitably reduced the total sample size. Third, major and minor amputation was not separately considered but was analyzed together as amputation event. First amputation event, major or minor, has its value but cannot reflect the severity of the outcome. Forth, death was not investigated in a disease specific manner and further investigation would be required. Lastly, this is a population-based study conducted in South Korea, and its findings may not necessarily be generalizable to the people of other countries with different medical insurance systems. Future studies that consider a more comprehensive range of factors including medication, laboratory data, and lifestyles are recommended to validate the findings of this study.

\section{Conclusions}

In conclusion, our results suggest that DFU patients with a low SEP are strongly associated with an increased rate of amputation and mortality. Hence, more attention needs to be given to such patients. Addressing SEP in patients with DFUs and providing targeted care for them may improve the prognosis.

\section{Abbreviations}

DFUs: Diabetic foot ulcers; SEP: Socioeconomic position; NHI: National health insurance; NHIS-NSC: National health insurance sharing service-national sample cohort; KCD: Korean classification of diseases; MA: Medical aid; ICD10: International classification of diseases, 10th revision; HR: Hazard ratio; $\mathrm{Cl}$ : Confidence interval

\section{Acknowledgements}

Not applicable.

\section{Authors' contributions}

JHH, HJJ, JUP performed data extraction, data cleaning, data analysis and interpretation, manuscript writing and critical review of the manuscript. All authors read and approved the final manuscript.

\section{Funding}

This work was supported by a public clinical research grant-in-aid from the Seoul Metropolitan Government Seoul National University (SMG-SNU) Boramae Medical Center (04-2021-0042) and SNUH Research Fund (No. 04-2018-0590). The funding body had no role in the design of the study and collection, analysis, and interpretation of data and in writing the manuscript.

\section{Availability of data and materials}

The datasets used and analysed during the current study are available from the corresponding author on reasonable request.

\section{Declarations}

Ethics approval and consent to participate

The Institutional Review Board of Seoul National University Boramae Medical Center (No. 07-2019-25) granted this study an exemption with regards ethical approval.

\section{Consent for publication}

Not applicable.

\section{Competing interests}

The authors declare that they have no competing interests.

\section{Author details}

${ }^{1}$ Department of Plastic and Reconstructive Surgery, Seoul National University Boramae Hospital, Seoul National University College of Medicine, Seoul 07061, Republic of Korea. ${ }^{2}$ Medical Research Collaborating Center, Seoul Metropolitan Government-Seoul National University Boramae Medical Center, Seoul 07061, South Korea.

Received: 7 December 2020 Accepted: 21 June 2021

Published online: 14 July 2021

\section{References}

1. Li X, Xiao T, Wang $Y, G$ G H, Liu Z, Jiang $Y$, et al. Incidence, risk factors for amputation among patients with diabetic foot ulcer in a Chinese tertiary hospital. Diabetes Res Clin Pract. 2011;93(1):26-30. https://doi.org/10.1016/j. diabres.2011.03.014

2. Lee KM, Kim WH, Lee JH, Choi MS. Risk factors of treatment failure in diabetic foot ulcer patients. Arch Plast Surg. 2013;40(2):123-8. https://doi. org/10.5999/aps.2013.40.2.123.

3. Jeon $\mathrm{H}$, Kim J, Yeo H, Jeong H, Son D, Han K. Treatment of diabetic foot ulcer using matriderm in comparison with a skin graft. Arch Plast Surg. 2013:40(4):403-8. https://doi.org/10.5999/aps.2013.40.4.403.

4. Walsh JW, Hoffstad OJ, Sullivan MO, Margolis DJ. Association of diabetic foot ulcer and death in a population-based cohort from the United Kingdom. Diabet Med. 2016;33(11):1493-8. https://doi.org/10.1111/dme.13 054.

5. Boyko EJ, Ahroni JH, Smith DG, Davignon D. Increased mortality associated with diabetic foot ulcer. Diabet Med. 1996;13(11):967-72. https://doi.org/1 0.1002/(SICI)1096-9136(199611)13:11<967::AID-DIA266>3.0.CO;2-K.

6. Jeffcoate WJ, Harding KG. Diabetic foot ulcers. Lancet. 2003;361(9368):154551. https://doi.org/10.1016/S0140-6736(03)13169-8.

7. Moulik PK, Mtonga R, Gill GV. Amputation and mortality in new-onset diabetic foot ulcers stratified by etiology. Diabetes Care. 2003;26(2):491-4. https://doi.org/10.2337/diacare.26.2.491.

8. Miyajima S, Shirai A, Yamamoto S, Okada N, Matsushita T. Risk factors for major limb amputations in diabetic foot gangrene patients. Diabetes Res Clin Pract. 2006;71(3):272-9. https://doi.org/10.1016/j.diabres.2005.07.005.

9. Brown AF, et al. Socioeconomic position and health among persons with diabetes mellitus: a conceptual framework and review of the literature. Epidemiol Rev. 2004;26(1):63-77. https://doi.org/10.1093/epirev/mxh002.

10. Blackwell DL, Hayward MD, Crimmins EM. Does childhood health affect chronic morbidity in later life? Soc Sci Med. 2001;52(8):1269-84. https://doi. org/10.1016/s0277-9536(00)00230-6.

11. Diez Roux AV, et al. Neighborhood of residence and incidence of coronary heart disease. N Engl J Med. 2001;345(2):99-106. https://doi.org/10.1056/ NEJM200107123450205.

12. Nather A, Bee CS, Huak CY, Chew JLL, Lin CB, Neo S, et al. Epidemiology of diabetic foot problems and predictive factors for limb loss. J Diabetes Complicat. 2008;22(2):77-82. https://doi.org/10.1016/j.jdiacomp.2007.04.004.

13. Monge L, Gnavi R, Carnà P, Broglio F, Boffano GM, Giorda CB. Incidence of hospitalization and mortality in patients with diabetic foot regardless of amputation: a population study. Acta Diabetol. 2020;57(2):221-8. https://doi. org/10.1007/s00592-019-01412-8.

14. Ikonen TS, Sund R, Venermo M, Winell K. Fewer major amputations among individuals with diabetes in Finland in 1997-2007: a population-based study. Diabetes Care. 2010;33(12):2598-603. https://doi.org/10.2337/dc10-0462.

15. Kennon B, Leese GP, Cochrane L, Colhoun H, Wild S, Stang D, et al. Reduced incidence of lower-extremity amputations in people with diabetes in 
Scotland: a nationwide study. Diabetes Care. 2012;35(12):2588-90. https:// doi.org/10.2337/dc12-0511.

16. Shaw J. Diabetes: regional variation in lower limb amputation incidence. Nat Rev Endocrinol. 2012;8(7):386-8. https://doi.org/10.1038/nrendo.2012.78.

17. Margolis DJ, Hoffstad O, Nafash J, Leonard CE, Freeman CP, Hennessy S, et al. Location, location, location: geographic clustering of lower-extremity amputation among Medicare beneficiaries with diabetes. Diabetes Care. 2011;34(11):2363-7. https://doi.org/10.2337/dc11-0807.

18. Kim HL, Kim J, Kim HJ, Lim WH, Lee JY. Incidence and factors associated with mortality in 2,476 patients with variant angina in Korea. Sci Rep. 2017; 7(1):46031. https://doi.org/10.1038/srep46031.

19. Son JS, Choi S, Kim K, Kim SM, Choi D, Lee G, et al. Association of Blood Pressure Classification in Korean young adults according to the 2017 American College of Cardiology/American Heart Association guidelines with subsequent cardiovascular disease events. JAMA. 2018;320(17):1783-92. https://doi.org/10.1001/jama.2018.16501.

20. Cheol Seong S, Kim YY, Khang YH, Heon Park J, Kang HJ, Lee H, et al. Data resource profile: the National Health Information Database of the National Health Insurance Service in South Korea. Int J Epidemiol. 2017:46:799-800. https://doi.org/10.1093/ije/dyw253.

21. Choi S, Kim K, Kim SM, Lee G, Jeong SM, Park SY, et al. Association of Obesity or weight change with coronary heart disease among young adults in South Korea. JAMA Intern Med. 2018;178(8):1060-8. https://doi.org/10.1 001/jamainternmed.2018.2310.

22. Kim GH, Lee JY, Kim J, Kim HJ, Park JU. Prevalence of Pressure Injuries Nationwide from 2009 to 2015: Results from the National Inpatient Sample Database in Korea. Int J Environ Res Public Health. 2019;16(5). https://doi. org/10.3390/ijerph16050704.

23. Eslami MH, Zayaruzny M, Fitzgerald GA. The adverse effects of race, insurance status, and low income on the rate of amputation in patients presenting with lower extremity ischemia. J Vasc Surg. 2007;45(1):55-9. https://doi.org/10.1016/j.jvs.2006.09.044.

24. Henry AJ, Hevelone ND, Belkin M, Nguyen LL. Socioeconomic and hospitalrelated predictors of amputation for critical limb ischemia. J Vasc Surg. 2011; 53:330-339 e331. https://doi.org/10.1016/j.jvs.2010.08.077.

25. Venermo $\mathrm{M}$, et al. Amputations and socioeconomic position among persons with diabetes mellitus, a population-based register study. BMJ Open. 2013;3. https://doi.org/10.1136/bmjopen-2012-002395.

26. Rucker-Whitaker C, Feinglass J, Pearce WH. Explaining racial variation in lower extremity amputation: a 5-year retrospective claims data and medical record review at an urban teaching hospital. Arch Surg. 2003;138(12):134751. https://doi.org/10.1001/archsurg.138.12.1347.

27. Laing P. The development and complications of diabetic foot ulcers. Am J Surg. 1998;176(2):11S-9S. https://doi.org/10.1016/s0002-9610(98)00182-2.

28. Jameson, J. L. Harrison's principles of internal medicine. Twentieth edition / edn, (McGraw-Hill Education, 2018).

29. Drinkwater JJ, Peters K, Davis WA, Turner AW, Bringans SD, Lipscombe RJ, et al. Assessment of biomarkers associated with rapid renal decline in the detection of retinopathy and its progression in type 2 diabetes: the Fremantle diabetes study phase II. J Diabetes Complicat. 2021;35(4):107853. https://doi.org/10.1016/j.jdiacomp.2021.107853.

30. Park HC, Lee YK, Cho AJ, Han C, Noh JW, Shin YJ, et al. Diabetic retinopathy is a prognostic factor for progression of chronic kidney disease in the patients with type 2 diabetes mellitus. PLoS One. 2019;14(7):e0220506. https://doi.org/10.1371/journal.pone.0220506.

31. Pavkov ME, Harding JL, Chou CF, Saaddine JB. Prevalence of diabetic retinopathy and associated mortality among diabetic adults with and without chronic kidney disease. Am J Ophthalmol. 2019;198:200-8. https:// doi.org/10.1016/j.ajo.2018.10.019.

32. Sellman $A$, Katzman $P$, Andreasson $S$, Londahl M. Presence of chronic diabetic foot ulcers is associated with more frequent and more advanced retinopathy. Diabet Med. 2018;35(10):1364-70. https://doi.org/10.1111/ dme.13682.

33. El-Asrar AM, Al-Rubeaan KA, Al-Amro SA, Moharram OA, Kangave D. Retinopathy as a predictor of other diabetic complications. Int Ophthalmol. 2001;24(1):1-11. https://doi.org/10.1023/a:1014409829614

34. Boulton AJ, Kirsner RS, Vileikyte L. Clinical practice. Neuropathic diabetic foot ulcers. N Engl J Med. 2004;351(1):48-55. https://doi.org/10.1056/NEJMcp032 966.

35. Hicks CW, Selvarajah S, Mathioudakis N, Sherman RL, Hines KF, Black JH III, et al. Burden of infected diabetic foot ulcers on hospital admissions and costs. Ann Vasc Surg. 2016;33:149-58. https://doi.org/10.1016/j.avsg.2015.11. 025.

36. Segreto F, Marangi GF, Nobile C, Alessandri-Bonetti M, Gregorj C, Cerbone V et al. Use of platelet-rich plasma and modified nanofat grafting in infected ulcers: technical refinements to improve regenerative and antimicrobial potential. Arch Plast Surg. 2020;47(3):217-22. https://doi.org/10.5999/aps.201 9.01571.

37. Lavery LA, Wunderlich RP, Tredwell JL. Disease management for the diabetic foot: effectiveness of a diabetic foot prevention program to reduce amputations and hospitalizations. Diabetes Res Clin Pract. 2005;70(1):31-7. https://doi.org/10.1016/j.diabres.2005.02.010

38. Dargis V, Pantelejeva O, Jonushaite A, Vileikyte L, Boulton AJ. Benefits of a multidisciplinary approach in the management of recurrent diabetic foot ulceration in Lithuania: a prospective study. Diabetes Care. 1999;22(9):142831. https://doi.org/10.2337/diacare.22.9.1428.

39. Holstein $P$, Ellitsgaard N, Olsen BB, Ellitsgaard V. Decreasing incidence of major amputations in people with diabetes. Diabetologia. 2000;43(7):844-7. https://doi.org/10.1007/s001250051459.

40. Patout CA Jr, Birke JA, Horswell R, Williams D, Cerise FP. Effectiveness of a comprehensive diabetes lower-extremity amputation prevention program in a predominantly low-income African-American population. Diabetes Care. 2000;23(9):1339-42. https://doi.org/10.2337/diacare.23.9.1339.

41. Apelqvist J, Larsson J. What is the most effective way to reduce incidence of amputation in the diabetic foot? Diabetes Metab Res Rev. 2000;16(Suppl 1):S75-83. https://doi.org/10.1002/1520-7560(200009/10)16:1+<::aid-dmrr13 9>3.0.co; $2-8$.

42. McCabe CJ, Stevenson RC, Dolan AM. Evaluation of a diabetic foot screening and protection programme. Diabet Med. 1998;15(1):80-4. https:// doi.org/10.1002/(SICI)1096-9136(199801)15:1<80:AID-DIA517>3.0.CO;2-K.

43. Task Force Team for Basic Statistical Study of Korean Diabetes Mellitus of Korean Diabetes, A, et al. Diabetes epidemics in Korea: reappraise nationwide survey of diabetes "diabetes in Korea 2007". Diabetes Metab J. 2013;37:233-9. https://doi.org/10.4093/dmj.2013.37.4.233.

44. Edelson GW, Armstrong DG, Lavery LA, Caicco G. The acutely infected diabetic foot is not adequately evaluated in an inpatient setting. Arch Intern Med. 1996;156(20):2373-8. https://doi.org/10.1001/archinte.1996.004401 90131013

\section{Publisher's Note}

Springer Nature remains neutral with regard to jurisdictional claims in published maps and institutional affiliations.

Ready to submit your research? Choose BMC and benefit from:

- fast, convenient online submission

- thorough peer review by experienced researchers in your field

- rapid publication on acceptance

- support for research data, including large and complex data types

- gold Open Access which fosters wider collaboration and increased citations

- maximum visibility for your research: over $100 \mathrm{M}$ website views per year

At BMC, research is always in progress.

Learn more biomedcentral.com/submissions 